\title{
Property turnover digitalisation: Interdisciplinary problems of post-classical jurisprudence
}

\author{
Liudmila Yurievna Vasilevskaya ${ }^{1 *}$, Vladimir Sergeyevich Belykh ${ }^{2}$, Tatiana Klavdievna \\ Primak $^{3}$, Ekaterina Borisovna Poduzova ${ }^{1}$, and Philipp Artemievich Tasalov ${ }^{4}$ \\ ${ }^{1}$ Kutafin Moscow State Law University, Department of Civil Law, Moscow, Russia \\ ${ }^{2}$ Ural State Law University, Department of Business Law, Yekaterinburg, Russia \\ ${ }^{3}$ Immanuel Kant Baltic Federal University, Law Institute, Kaliningrad, Russia \\ ${ }^{4}$ RTS-Tender LLC, Legal Division, Moscow, Russia
}

\begin{abstract}
The purpose of the research is to consider the key interdisciplinary research and practice problems of the property turnover digitalisation and propose ways to solve them. Elements, phenomena and processes of the digital environment first appeared in the countries of the Anglo-Saxon legal family. By determining the constitutive features of them, the authors turned to classical domestic and foreign legal statutory concepts and policy management. The research was carried out by the comparativelegal method and modelling method. The identification of interdisciplinary research and practice problems as well as methods for solving them was based on the methods for ascent from the abstract to the concrete, induction and deduction. As a result of the implementation of the research objectives through the general scientific and private scientific methods described above, the authors identified the constitutive features of the key elements of property turnover in the digital environment, such as digital currency, smart contract, electronic trading. Identified were both doctrinal and practical problems associated with the essence and features of those elements, as well as the legal regulation of the associated relations. Those elements are considered in two dimensions, in the information system and legal field. In addition, significant gaps in the regulatory framework of the associated relations were identified; the impossibility of applying the classical regime of objects of civil rights and the rules of documentary circulation to digital objects and processes was substantiated. The novelty of the work consists in proposing ways to solve interdisciplinary theoretical and practical problems of the property turnover digitalisation, which are important for a wide range of academic researchers and practitioners in the legal field.
\end{abstract}

Keywords: digital currency, contract, agreement, document

\section{Introduction}

The rapid growth of the collaborative economy in 2010 marked the final creation of the digital social and economic system as a new basis for the modern civilisation and culture that can be characterised by such features as widespread and mass adoption of digital technologies

* Corresponding author: liudmila.vasilevskaya@gmail.com 
in all areas of public life; maximum simplification and acceleration of the economic and social interaction; the focus on saving time and other resources; development of modes alternative to property rights, as the basis for business activities. The new system sets innovative research goals for legal sciences since the digital socio-economic interaction cannot be fully implemented without a proper regulatory framework. A new task of the postclassical jurisprudence is to address interdisciplinary issues associated with the property turnover digitalisation.

The civil circulation digitalisation is increasingly developing in the context of the digital socio-economic paradigm. Objects, phenomena and processes of the information system (digital rights, digital currency, smart contracts, electronic document management, electronic trading etc.) have been adopted in the property circulation and are increasingly becoming in demand among legal entities. Digitalisation has caused a surge in publication activities in the field of legal research. Objects, phenomena and processes of the digital system have been studied by many authors over the past 5 years. However, in most research papers, the provisions of law governing classical property relations outside the framework of the information system are incorrectly applied to those elements of the digital environment from a legal point of view. An example of that is the article in which the authors recognize the properties and status of the subject of law as "artificial intelligence" [1]. "Artificial intelligence" is the outcome of complex programming. It is appropriate to speak of "artificial intelligence" as an object of a right.

The authors of this work were among the first to propose to distinguish between digital interaction and relationship at law; they criticised the application of classical legal concepts to new digital objects, phenomena and processes. An approach to qualification of digital currency, smart contract, digital trading is proposed; conclusions and proposals are made regarding the regulatory framework of the corresponding relations and the impossibility of regulating them in a similar way to classical relations that are part of the subject of various branches of law.

To substantiate this hypothesis, formulated were such research objectives as to consider the key interdisciplinary research and practice problems of digitalisation of property turnover and propose ways to solve them. To achieve those goals, some tasks were set and implemented, namely to analyse the current state of the digital environment, property turnover, legislation and scientific doctrine; identify research and practice problems related to digital currency, smart contracts and digital trading; substantiate the proposed ways of solving interdisciplinary research and practice problems.

\section{Methods}

Elements, phenomena and processes of the digital environment first appeared in the countries of the Anglo-Saxon legal family. In determining their constitutive features, the authors turned to classical domestic and foreign legal constructions and regulatory framework. The research was carried out with the comparative-legal method and modelling method. The identification of interdisciplinary scientific and practical problems and methods of their solution was based on the methods of ascent from the abstract to the concrete, induction and deduction.

The research results are presented in Table 1.

Table 1. Research results.

\begin{tabular}{|c|c|c|c|}
\hline No. & $\begin{array}{c}\text { Area of property } \\
\text { turnover } \\
\text { digitalisation }\end{array}$ & $\begin{array}{c}\text { Interdisciplinary } \\
\text { research and practice } \\
\text { problem }\end{array}$ & Proposed method of solution \\
\hline 1. & digital currency & legal essence & digital cashless money \\
\hline 2. & digital currency & property turnover item & digital law, \\
\hline
\end{tabular}




\begin{tabular}{|c|c|c|c|}
\hline & & & digital financial asset \\
\hline 3. & smart contract & essence & programme code \\
\hline 4. & smart contract & legal content & $\begin{array}{c}\text { method of entry into and (or) } \\
\text { performance of the contract }\end{array}$ \\
\hline 5. & electronic auction & data verification & state information systems \\
\hline 6. & electronic auction & electronic auction rules & $\begin{array}{c}\text { personal data protection, integration, } \\
\text { expansion of the negotiation practice }\end{array}$ \\
\hline
\end{tabular}

\section{Discussion}

The property turnover digitalisation influences various areas of interaction between legal entities, such as digital currency transactions, contractual digital interaction, entry into contracts and selection of counterparties in the digital environment. Those areas of interaction are associated with digital currency, smart contract and digital trading - categories of postclassical jurisprudence that are complex and/or cross-sectoral in nature. It is the interdisciplinary approach in jurisprudence that makes it possible to identify the research and practice problems of the digital property turnover in private law, which makes it possible to identify the civil legal essence of the categories under consideration.

In particular, digital currency [2], which exists only in the information system, can be visualised in it in a special tangible, intangible form, i.e. digital [3], which cannot be considered the monetary unit of the state. This means that digital currency is a conditional concept: it is not the currency of the Russian Federation, since, in accordance with the law, it is only the rouble [4]. Digital currency is not money since money, from the point of view of civil law, is the banknotes and coins of the Bank of Russia in circulation in the territory of the Russian Federation [5]. Therefore, any title to digital currency or its vindication will be out of the question. The owner of a digital currency cannot have a title to it, this is excluded by the very legal nature of this object of property turnover [6].

By law, digital currency is a means of payment that is excluded from circulation as a counter-provision for transferred goods, work performed and services rendered, but it can be used in transactions involving the transfer of digital currency from one person to another when using objects of the Russian information infrastructure. Consequently, the limitation of the circulability of digital currency makes it possible to qualify it as a digital non-cash money that is not a generally mandatory (legal) means of payment and is related by its legal nature to a certain type of property, namely the pecuniary right of claim. The property nature of digital currency allowed the legislator to consider it as an investment as an independent object of civil turnover; it can be alienated on a reimbursable and gratuitous basis, pledged, bequeathed, or otherwise disposed of in compliance with all the rules provided by law.

The qualification of a smart contract as a self-executing contract overlooks its important function. As a programme code, it can not only be used for the contract implementation but also its conclusion, as well as for those cases when the time of entry into and implementation of the contract match. A digital contract entered into with a smart contract is subject to the general contracting rules [7]. Blockchain technology [8] is not the only applicable technology for a smart contract [9], and other distributed ledger technologies are also used. The Russian legislation does not establish any restrictions on the types of technologies used. The person, that uses a programme code - a smart contract, independently chooses the DLT (technology) that is most practically convenient and financially profitable for him/her.

The smart contract has been implemented into the Russian digital socio-economic paradigm from the Anglo-Saxon business practice [10]. The definition of concepts, the nature of legal structures and the legal qualification of contracts are a constitutive feature of the Romano-Germanic legal family, a significant part of the elements which was adopted by the Russian legal system. The Anglo-American legal system has no such properties [11], which 
allows legal entities to use new and often unnamed legal constructions more freely. In this regard, it is inappropriate to subordinate the Anglo-Saxon model to a rather rigid framework of the Russian legal system by trying to translate the programme code into a contractual form. The programme code can be used in business practice regardless of the availability or nonavailability of a contract.

The translation of most forms of public procurement bidding into electronic form completed in Russia in 2019 was accompanied by the refusal of the legislator from hard-copy document workflow [12].

One of the advantages of e-procurement is the absence of the need for physical contact between legal entities [13], which was clearly shown by the coronavirus pandemic, when customers used not only the electronic tender form but also the possibility of remotely considering bids by members of procurement commissions.

At the same time, the translation of procurement into electronic form did not lead to a simplification of the Russian procurement system for its main players, customers and suppliers. The legislator did not solve the problems of verification by the customer of the data specified by the supplier in the application form, as well as the ratio of an electronic document and its hard copy. Until now, the optimal e-procurement model has remained uncertain [14]. Solving those problems would make it possible for the customer to take into account the specifics of the purchased products, ranging from the purchase of simple goods common in the market to construction contracts. Digitalisation has further strengthened blocking any negotiations between the procurement parties and customer at the legislative level [15]. The change in the form of procurement from paper-based to electronic [16] not only failed to provide a solution to previously accumulated problems but also led to the emergence of new challenges already in the digital environment.

Despite the widespread adoption of electronic document management, customers are deprived of the opportunity to verify the compliance of procurement parties with the requirements imposed on them on the basis of state information systems and interdepartmental electronic interaction.

For business, digitalisation has turned into the need for the constant use of many private and state information systems, such as the operators of electronic platforms, a unified information system, a unified authentication and identification system, electronic stores constantly experiencing integration problems and failures.

\section{Conclusion}

The analysis of the key elements of digital interaction between property turnover participants allows us to draw the following conclusions.

First, while being in a special (intangible) tangible, digital form, this (digital) "currency" as a right of claim is a kind of digital law, and therefore, as a digital financial asset, unlike cryptocurrency, it is not a monetary surrogate and belongs to digital "non-cash money" issued by individuals.

Secondly, a smart contract is a programme code through which operations are performed to exchange and (or) provide tangible benefits, it is this essence of a smart contract that is expressed in not only the latest changes in civil legislation but also in information memos of the Central Bank of the Russian Federation.

Thirdly, the procurement digitalisation has led to the complication of legislation in the field of public procurement and the practice of its application increased blocking by the legislator of the negotiating opportunities of the parties; the advantages of the electronic form of bidding and procurement turned out to be offset by its costs, such as unresolved issues of interaction and integration of information systems, the lack of effective mechanisms for 
protecting personal data, differentiating an electronic document and its paper copy, as well as a unified (antimonopoly and judicial) law enforcement practice.

\section{References}

1. D.L. Kuteinikov, O.A. Izhaev, V.A. Lebedev, S.S. Zenin, Lex Russica, 9, 85-95 (2019). https://doi.org/10.17803/1729-5920.2019.154.9.085-095

2. R. Galiautdinov, Globalization, Economic Crises, and Disintegration Processes in Eurasia (2020). Accessed on: February 16, 2021. [Online]. Available:

https://www.researchgate.net/publication/340298354_Cryptocurrency_in_digital_economy_and_crypto-currency_IT_aspects

3. L. Yu. Vasilevskaya, Economy and Law, 5(508), 3-14 (2019). Accessed on: June 24, 2021. [Online]. Available: https://elibrary.ru/item.asp?id=37422238

4. F. García-Monleón, I. Danvila del Valle, J. Francisco Lara, Technological Forecasting and Social Change, 162, 120393 (2021). https://doi.org/10.1016/j.techfore.2020.120393

5. D. Teker, E. Asena Deniz, Pressacademia, 11(1), 34-37 (2020). https://doi.org/10.17261/Pressacademia.2020.1235

6. L.Yu. Vasilevskaya, Actual Problems of the Russian Law, 5(102), 111-119 (2019). https://doi.org/10.17803/1994-1471.2019.102.5.111-119

7. G. Rühl, Blockchain, Law and Governance, 159-180 (2020). https://doi.org/10.1007/978-3-030-52722-8_11

8. S. K. Dutta, The Definitive Guide to Blockchain for Accounting and Business: Understanding the Revolutionary Technology, 61-78 (2020). https://doi.org/10.1108/978-1-78973-865-020201005

9. M. Bartoletti, Frontiers in Blockchain, 3 (2020). https://doi.org/10.3389/fbloc.2020.00027

10. E.B. Poduzova, Actual Problems of the Russian Law, 8, 86-94 (2019). https://doi.org/10.17803/1994-1471.2019.105.8.086-094

11. E.B. Poduzova, Lex Russica, 6, 116-128 (2017). https://doi.org/10.17803/17295920.2017.127.6.116-128

12. F.A. Tasalov, Actual Problems of the Russian Law, 1, 116-125 (2017). https://doi.org/10.17803/1994-1471.2017.74.1.116-125

13. C. David, Construction Contracts, 1-6 (2020). https://doi.org/10.4324/97810030809301

14. K. Hughes, Understanding the NEC4 Professional Service Contract, 170-184 (2020). https://doi.org/10.4324/9781003020059-12

15. F.A. Tasalov, Actual Problems of the Russian Law, 2, 85-94 (2019). https://doi.org/10.17803/1994-1471.2019.99.2.085-094

16. C. T. W. Chan, Estimating and Measurement for Simple Building Works in Hong Kong, 50-65 (2020). https://doi.org/10.1201/9781003017837-6 